\title{
Historic Characters and Famous Events
}

\section{Gaye Chan}

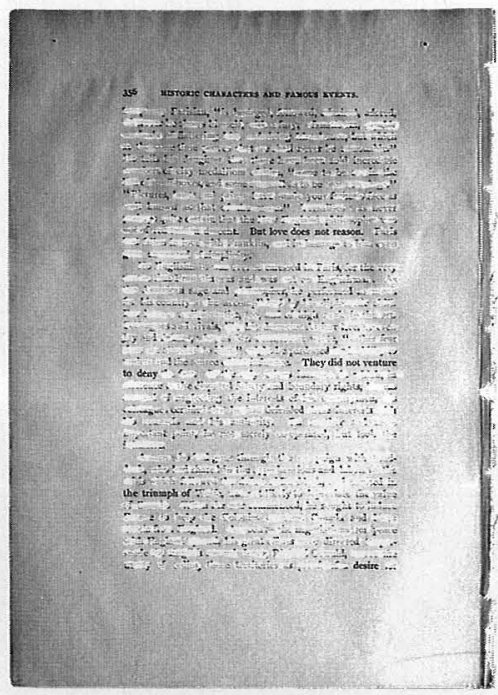

Story A - page 4, 1999-2000, digital image and acrylic on paper, $9.75^{\prime \prime} \times 7^{\prime \prime}$

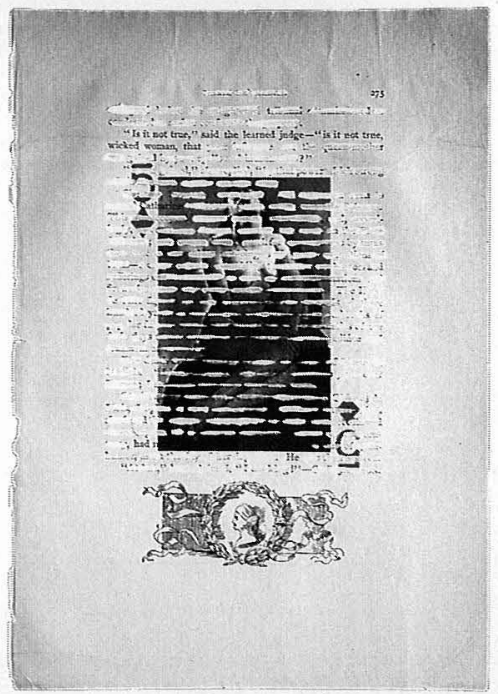

Story C - page 4, 1999-2000, digital image and acrylic on paper, $9.75^{\prime \prime} \times 7^{\prime \prime}$ 


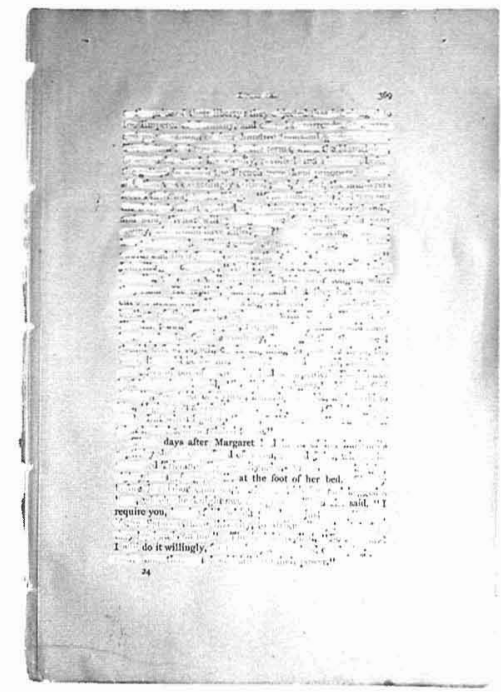

Story A-page 5, 1999-2000, digital image and acrylic on paper, $9.75^{\prime \prime} \times 7^{\prime \prime}$

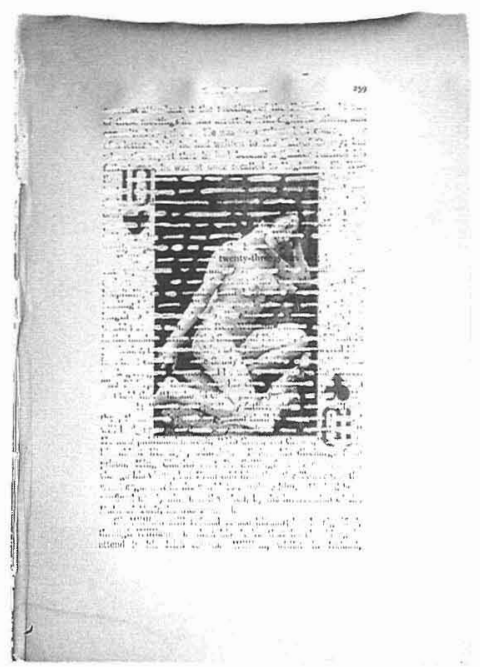

Story $Q$ - page 1, 1999-2000, digital image and acrylic on paper, $9.75^{\prime \prime} \times 7^{\prime \prime}$ 


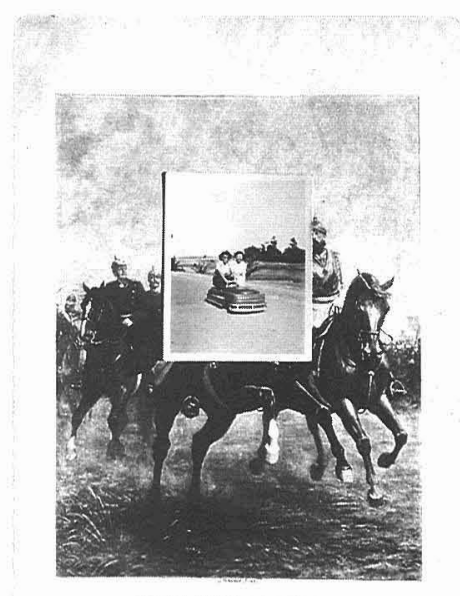

yaprog :

Emperor William I and his Suite, 1999-2000, silver gelatin print on paper, $9.75^{\prime \prime} \times 7^{\prime \prime}$

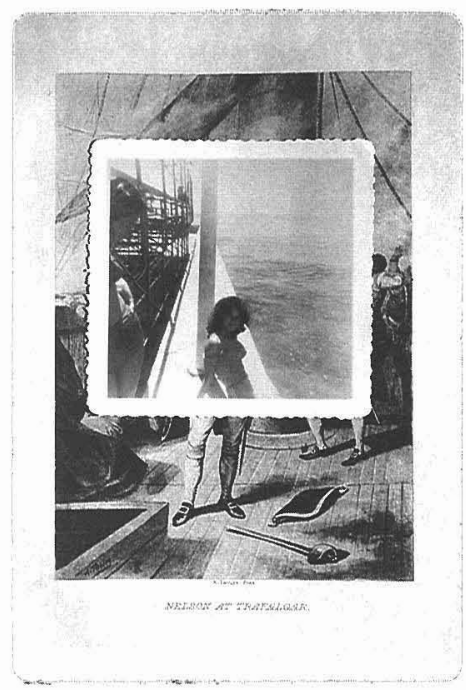

Nelson at Trafalgar, 1999-2000, silver gelatin print on paper, $9.75^{\prime \prime} \times 7^{\prime \prime}$ 